\title{
Primeiro registro de Leptogorgia punicea (Milne-Edwards \& Haime) (Cnidaria, Octocorallia) para o Estado do Maranhão, Brasil
}

\author{
Carlos D. Pérez
}

Grupo de Pesquisa em Antozoários, Núcleo de Estudos em Cnidaria, Departamento de Zoologia, Universidade Federal de Pernambuco. Avenida Professor Moraes Rêgo 1235, Cidade Universitária, 50670-901 Recife, Pernambuco, Brasil.

E-mail: cdperez@ufpe.br

\begin{abstract}
First record of Leptogorgia punicea (Milne-Edwards \& Haime) (Cnidaria, Octocorallia) from Maranhão State, Brazil. A small colony of Leptogorgia punicea (Milne-Edwards \& Haime, 1857) was sampled in the intertidal zone of Marcela beach. This sample represents the first record from Maranhão State, making continuous the distribution of this species along the western American coast.

KEY WORDS. Alcyonacea, geographic distribution, Gorgoniidae, Western Atlantic.
\end{abstract}

RESUMO. Foi coletada uma pequena colônia de Leptogorgia punicea (Milne-Edwards \& Haime, 1857) no mediolitoral da praia da Marcela. A coleta representa o primeiro registro para o Estado do Maranhão, tornando continua sua distribuição ao longo da costa ocidental americana.

PALAVRAS CHAVE. Alcyonacea, Atlântico Ocidental, distribuição, Gorgoniidae.

Os octocorais do Atlântico Norte Ocidental de águas tropicais ou temperadas são relativamente bem conhecidos, mas as espécies que ocorrem ao sul do Rio Amazonas, apesar de possuírem elementos em comum com a fauna antilhana, são pouco conhecidas (BAYER 1981). Das 59 espécies de octocorais descritas para o litoral brasileiro, 25 ocorrem na região Nordeste $(42,37$ $\%)$, sendo o estado da Bahia o que apresenta a maior quantidade (17) (SiLva \& Pérez 2002).

Os registros de octocorais no litoral maranhense são escassos, existindo apenas sete espécies, das 59 espécies registradas para o Brasil: Phyllogorgia dilatata (Esper, 1806), Carijoa riisei (Duchassaing \& Michelotti, 1860), Scleracis guadalupensis (Duchassaing \& Michelotti, 1860), Plexaurela dichotoma (Esper, 1791), Leptogorgia miniata (Milne-Edwards \& Haime, 1857), Pacifigorgia elegans (Milne-Edwards \& Haime, 1857) e uma espécie de Muriceopsis sp. registrada por Medeiros \& Castro (1999) (Castro \& Pires 2001, Silva \& Pérez 2002). As poucas descrições do grupo para o litoral do Maranhão, em relação à fauna caribenha ou a própria fauna brasileira de outras regiões do país (SANCHEZ 1994), se explicam pelo pequeno número de pesquisas realizadas na área e pela ausência de especialistas no Estado.

O objetivo do presente trabalho é descrever o primeiro registro do octocoral Leptogorgia punicea (Milne-Edwards \& Haime, 1857) para o litoral maranhense.

\section{MATERIAL E MÉTODOS}

O material foi coletado manualmente, em poça de maré, no mês de outubro de 2001 na Praia da Marcela na cidade de São Luís do Estado do Maranhão, e fixado in situ em álcool $70 \%$. No laboratório, foram feitas as análises macroscópicas, em estereomicroscópio, da forma da colônia e dos cálices, estrutura antocodial e distribuição dos pólipos. Após a maceração de partes da colônia em hipoclorito de sódio, analisou-se escleritas com a ajuda de microscópio óptico.

O exemplar foi depositado na coleção de antozoários do Grupo de Pesquisa em Antozoários (G.P.A.), Núcleo de Estudos em Cnidaria, Departamento de Zoologia, Universidade Federal de Pernambuco.

\section{RESULTADOS}

Alcyonacea Lamouroux, 1816 sensu Bayer, 1981 Gorgoniidae Lamouroux, 1812

Leptogorgia punicea (Milne-Edwards \& Haime, 1857)

Diagnose. Ver BAYER (1961: 204-207).

Material examinado. Fragmento de uma colônia da Praia da Marcela, São Luís, Maranhão, 02³9'S 44²15'W, 08/X/2001, em poça de maré, Bruno Tenório leg., G.P.A. nº 152.

Revista Brasileira de Zoologia 22 (3): 810-811, setembro 2005 
Descrição: Colônia arborescente, 10,5 cm de comprimento, irregularmente peniforme, com ramificação em um plano. Pólipos dispostos em fileiras duplas e alternadas, em ambos os lados dos ramos terminais. Cálices proeminentes. Armadura antocodial desenvolvida, com oito pontas em "chevron" e colarinho não delimitado claramente. Escleritas do antocódio rosas, incolores ou mistas, em forma de bastões e varas achatadas de contornos irregulares (0,071-0,10 mm). Escleritas do córtex púrpuras, vermelhas, rosas ou de coloração mista, em forma de fusos cabestrantes com extremidades afiladas ou arredondadas $(0,098 \mathrm{~mm})$, presença de grandes fusos com tubérculos isolados $(0,13 \mathrm{~mm})$. Cálices com escleritas incolores em forma de fusos cabestrantes $(0,082 \mathrm{~mm})$, fusos com cintura tuberculados $(0,075 \mathrm{~mm})$, ovais tuberculados $(0,055 \mathrm{~mm})$ e algumas com cabeça dupla $(0,055 \mathrm{~mm})$. Colônia de cor púrpurarosácea, cálices brancos.

Distribuição. Santa Catarina até a Bahia no Brasil, e do Suriname até Carolina do Norte nos EUA (BAYER 1961, HeTzel \& CASTRO 1994). O registro para o litoral maranhense vem cobrir o hiato existente na distribuição de L. punicea, tornando-a mais contínua ao longo da costa atlântica americana.

Observações. A continuidade na distribuição geográfica da espécie L punicea ao longo da costa leste americana (Carolina do Norte-Santa Catarina) tornaria esta espécie tipicamente tropical com incidência subtropical, reafirmando o endemismo no Oceano Atlântico Ocidental. Com este novo registro, "link" entre as populacoes caribenhas e brasileiras, se apoia a ideia de que L. puniceea é uma espécie com grande plasticidade fenotípica em estruturas morfologicas maleáveis pelos diferentes ambientes (ramificação, tamanho, cor, etc), mas com uma aparente regularidade nas estruturas diagnósticas como tipo e tamanho das escleritas.

\section{AGRADECIMENTOS}

A Bruno T. da Silva pela coleta e ajuda na descrição do material, a bióloga Luciana C. Gusmão pela tradução do resumo, e a Dra. Paula Braga Gomes pela leitura crítica do manuscrito.

\section{REFERÊNCIAS BIBLIOGRÁFICAS}

BAYER, F.M. 1961. The Shallow-Water Octocorallia of the West Indian Region. A manual for marine biologist. Haya, Fauna Curação and other Caribbean Islands, vol. 12, 373p.

BAYER, F.M. 1981. Status of knowledge of octocorals of world seas, p 3-11. In: Academia Brasileira De Ciências (Ed.). Seminários de Biologia Marinha. Rio de Janeiro, Academia Brasileira de Ciências, 383p.

Castro, C.B. \& D.O. Pires. 2001. Brazilian coral reefs: what we already know and what is still missing. Bulletin of Marine Science, Miami, 69 (2): 357-371.

Hetzel, B. \& C.B. Castro. 1994. Corais do Sul da Bahia. Rio de Janeiro, Nova Fronteira, 189p.

Medeiros, M.S. \& C.B. CAstro. 1999. Paramuriceidae e Plexauridae (Cnidaria, Octocorallia) do Brasil: batimetria e distribuição geográfica. Boletim do Museu Nacional, Rio de Janeiro, 398: 1-20.

SANCHEZ, J.A. 1994. Presencia de los octocorales Stylatula diadema Bayer (Pennatulacea) y Carijoa riisei (Duchassaing \& Michelotti) (Telestacea) en la costa Caribe Colombiana. Anales del Instituto de Investigaciones Marinas de Punta Bétin, Santa Marta, 23: 137-147.

Silva, B.T. \& C.D. Pérez. 2002. Diagnosis del conocimiento de la fauna de octocorales (Cnidaria, Anthozoa) de la región Nordeste de Brasil. Tropical Oceanography, Recife, 30 (1): 15-22.

Recebido em 21.I.2005; aceito em 17.VIII.2005. 